\title{
A comparison of brain heart infusion blood agar sterilized by filtration and heat on the growth of Neisseria gonorrhoeae
}

\author{
A. D. SETH AND A. E. WILKINSON
}

From the Venereal Diseases Reference Laboratory (PHLS), London Hospital Research Laboratories, Ashfield Street, London E1 2BL

SYNOPSIS The growth of Neisseria gonorrhoeae on brain heart infusion blood agar in which the base was sterilized by filtration has been compared with growth on the same medium sterilized by heat. Colonies were larger on the unheated medium, and autoclaving at $115^{\circ} \mathrm{C}$ or $121^{\circ} \mathrm{C}$ for 15 minutes was accompanied by a progressive decrease in colony size. Viable counts on the three media showed no difference in end points. Colonies on the unheated medium were usually large enough to be easily recognizable after overnight incubation.

The routine medium used for the isolation of Neisseria gonorrhoeae in this laboratory is brain heart infusion agar with $10 \%$ horse blood and vancomycin, $3 \mu \mathrm{g} / \mathrm{ml}$, and colistin, $7 \cdot 5 \mu \mathrm{g} / \mathrm{ml}$. This usually gives a good growth of gonococci with colonies about $1-2 \mathrm{~mm}$ in diameter after incubation for 48 hours in $10 \% \mathrm{CO}_{2}$, but over a period it was noticed that the colonies were extremely small, which made identification difficult. Enquiries suggested that the basal medium might have been left in the autoclave for an unduly long time. This led to an examination of the effect of the temperature of sterilization and sterilization by filtration on the colony size and density of growth of gonococci.

\section{Material and methods}

\section{BRAIN HEART INFUSION AGAR (OXOID CM 375)}

Of the dehydrated medium, $14 \cdot 1 \mathrm{~g}$ was suspended in $267 \mathrm{ml}$ of distilled water and left at room temperature for 30 minutes. This basal medium was autoclaved at $121^{\circ} \mathrm{C}$ for 15 minutes, cooled to $48^{\circ} \mathrm{C}$, and $30 \mathrm{ml}$ horse blood (Oxoid SR 50) and $3 \mathrm{ml}$ of mixed antibiotic solution containing equal parts of vancomycin $0.06 \%$ and colistin $0.15 \%$ were added to give final concentrations of vancomycin, $3 \mu \mathrm{g} / \mathrm{ml}$, and colistin, $7.5 \mu \mathrm{g} / \mathrm{ml}$. After thorough mixing plates were poured. This medium is designated $\mathrm{BH} 121 / 15$. Received for publication 3 April 1976
UNHEATED BRAIN HEART INFUSION AGAR Double strength brain heart infusion (Oxoid CM 225) was prepared by dissolving $74 \mathrm{~g}$ in one litre of distilled water, sterilized by seitz filtration, and stored at $4^{\circ} \mathrm{C}$. For use, $150 \mathrm{ml}$ of this base was warmed to $48^{\circ} \mathrm{C}$ and mixed with $117 \mathrm{ml}$ of $2.5 \%$ melted Oxoid Agar No. 1 cooled to the same temperature. Thirty millilitres of horse blood and antibiotics were added as before (BHF medium). For some experiments the filter sterilized base was subsequently sterilized at $115^{\circ} \mathrm{C}$ or $121^{\circ} \mathrm{C}$ for 15 minutes. When cooled to $48^{\circ} \mathrm{C}$ agar, blood and antibiotics were added as before. These media are designated BHF 115/15 and BHF 121/15.

PREPARATION OF INOCULA

These were prepared from:

(a) urethral discharge collected on a swab from males with acute gonococcal urethritis, suspended in $1 \mathrm{ml}$ broth and diluted 1 in 10 in broth;

(b) 24-hour subcultures from primary plates suspended in broth to a turbidity corresponding to between McFarland tubes 1 and 2. Serial 10-fold dilutions in broth were spread on the plates to be compared which were incubated at $36^{\circ} \mathrm{C}$ in candle jars. In some tests strains which had been subcultured several times were examined. All strains tested were identified as gonococci by their microscopical appearance, the oxidase test, and fermentation reactions. 
MEASUREMENT OF COLONIES

This was done on plates which showed discrete colonies. The diameters of 20 or 25 consecutive well separated colonies were measured with a calibrated eyepiece micrometer and a Leitz Ultropak vertical illuminator at a magnification of $\times 22 \cdot 8$.

\section{Results}

The mean diameters of colonies from five primary isolates, 13 subcultures from primary isolates and two stock strains on the filtered medium, filtered and then autoclaved medium and routine medium autoclaved at $121^{\circ} \mathrm{C}$ for 15 minutes are shown in table I.

Colonies on the filtered medium were consistently larger than those on the medium made from the same constituents but which had been autoclaved. This difference was apparent after incubation for both 24 and 48 hours. Three strains showed no measurable growth when first examined after 24 hours.

In a second experiment, a comparison was made of the colony size of three primary isolates on the filtered medium and on the same medium in which the base had been autoclaved at $115^{\circ} \mathrm{C}$ or $121^{\circ} \mathrm{C}$ for 15 minutes (table II).

With these three strains, autoclaving the medium

\begin{tabular}{|c|c|c|c|c|}
\hline \multirow[t]{3}{*}{ Strain } & \multicolumn{4}{|c|}{ Medium } \\
\hline & $B H F$ & BHF $121 / 15$ & $B H F$ & BHF 121/15 \\
\hline & \multicolumn{2}{|c|}{$24 h$ incubation } & \multicolumn{2}{|c|}{$48 h$ incubation } \\
\hline \multicolumn{5}{|l|}{ Primary isolates } \\
\hline $\mathbf{G}$ & 0.87 & 0.70 & $1 \cdot 40$ & $1 \cdot 21$ \\
\hline G3 & 0.48 & 0.24 & $1 \cdot 55$ & 0.80 \\
\hline G4 & 0.69 & 0.36 & $2 \cdot 10$ & 148 \\
\hline G5 & 0.84 & 0.54 & $2 \cdot 02$ & $1 \cdot 40$ \\
\hline G61 & $0 \cdot 20$ & $0 \cdot 26$ & $1 \cdot 14$ & 0.98 \\
\hline \multicolumn{5}{|l|}{ First subculture } \\
\hline from primary & $B H F$ & BH 121/15 & $B H F$ & $\mathrm{BH} 121 / 15$ \\
\hline 179 & $1 \cdot 24$ & 0.91 & $2 \cdot 89$ & 1.96 \\
\hline 312 & NG & NG & $2 \cdot 01$ & 0.87 \\
\hline 310 & $1 \cdot 29$ & 0.85 & $3 \cdot 74$ & $2 \cdot 7$ \\
\hline 315 & $1 \cdot 06$ & 0.81 & $3 \cdot 12$ & $2 \cdot 46$ \\
\hline 340 & 0.59 & 0.40 & $1 \cdot 11$ & 1.01 \\
\hline 287 & $1 \cdot 12$ & $1 \cdot 01$ & $3 \cdot 16$ & $2 \cdot 99$ \\
\hline 304 & $1 \cdot 28$ & 0.83 & $2 \cdot 67$ & $1 \cdot 79$ \\
\hline WAK & 0.92 & NG & $2 \cdot 23$ & 1.08 \\
\hline 213 & $1 \cdot 26$ & 0.87 & $3 \cdot 17$ & $1 \cdot 25$ \\
\hline 341 & 0.49 & 0.25 & $1 \cdot 19$ & 0.57 \\
\hline 270 & NG & NG & 1.97 & $1 \cdot 50$ \\
\hline 319 & NG & NG & 1.67 & $1 \cdot 18$ \\
\hline G3a & 1.42 & 1.46 & $2 \cdot 04$ & $2 \cdot 51$ \\
\hline \multicolumn{5}{|l|}{ Stock strain } \\
\hline $3 \mathbf{R}$ & $1 \cdot 12$ & 0.65 & - & - \\
\hline $\mathrm{G6}^{1}$ & 0.71 & 0.66 & $2 \cdot 56$ & $2 \cdot 15$ \\
\hline
\end{tabular}

Table I Mean diameter $(\mathrm{mm})$ of colonies of gonococci on filtered medium $(B H F)$, filtered and autoclaved medium (BHF 121/15), and medium autoclaved at $121^{\circ} \mathrm{C}$ for 15 minutes $(\mathrm{BH} 121 / 15)$

NG $=$ no visible growth.

ISame isolate. at $121^{\circ} \mathrm{C}$ halved the colony size after 24 hours' incubation, and after autoclaving at $115^{\circ} \mathrm{C}$ the colonies were only three-quarters the size of those on the filtered medium.

These tests showed that medium sterilized by filtration promoted a more rapid growth of gonococci than when the medium was sterilized by heat. To find whether it would promote giowth from a smaller inoculum, $0.025 \mathrm{ml}$ volumes of serial dilutions in broth of suspensions of urethral pus from 12 males with acute gonorrhoea were spotted on plates of the two media. When read after 48 hours' incubation there were no significant differences in the endpoints. This suggests that although gonococci grew more rapidly on the filtered medium, its sensitivity was not greater than the medium autoclaved at $115^{\circ} \mathrm{C}$ or $121^{\circ} \mathrm{C}$.

To compare the performance of the filtered and autoclaved media under working conditions, 636 urethral swabs from male patients were examined; these were from both treated and untreated patients and were sent to the laboratory on buffered swabs in Stuart's transport medium containing carbon. The order of plating on the two media was alternated. The results are shown in table III.

\begin{tabular}{|c|c|c|c|c|c|c|}
\hline \multirow[t]{3}{*}{ Medium } & \multicolumn{6}{|c|}{ Strain } \\
\hline & \multicolumn{2}{|c|}{ No. 1230} & \multicolumn{2}{|c|}{ No. 1300} & \multicolumn{2}{|c|}{ No. 1444} \\
\hline & $24 h$ & $48 h$ & $24 h$ & $48 h$ & $24 h$ & $48 h$ \\
\hline $\begin{array}{l}\text { Filtered } \\
\text { Fil.ered and }\end{array}$ & 0.56 & $1 \cdot 28$ & 0.34 & $1 \cdot 26$ & 0.79 & $1 \cdot 43$ \\
\hline $\begin{array}{l}\text { autoclaved 115/15 } \\
\text { Filtered and }\end{array}$ & 0.46 & 0.96 & 0.25 & 0.92 & 0.62 & $1 \cdot 26$ \\
\hline autoclaved $121 / 15$ & 0.27 & 0.87 & 0.14 & 0.64 & 0.42 & 0.88 \\
\hline
\end{tabular}

Table II Mean colony diameters $(\mathrm{mm})$ of primary cultures of gonococci on filtered medium and filtered and autoclaved medium

\begin{tabular}{lll}
\hline & $\begin{array}{l}\text { Filtered medium } \\
(B H F)\end{array}$ & $\begin{array}{l}\text { Autoclaved medium } \\
(B H \text { 121/15) }\end{array}$ \\
\hline No gonococci grown & 558 & 565 \\
Gonococci grown & 78 & 71 \\
Growth visible after $24 \mathrm{~h}$ & 67 & 37 \\
$\begin{array}{l}\text { Growth visible only } \\
\text { after 48 h }\end{array}$ & 11 & 34 \\
\hline
\end{tabular}

Table III Routine cultures of urethral swabs from 636 males on filtered and autoclaved media

Two strains were isolated on the autoclaved but not the filtered medium and nine on the filtered but not the autoclaved medium. Growth on the filtered medium was more rapid, and colonies were present in most instances after overnight incubation. 


\section{Discussion}

The introduction of media made selective for gonococci by the addition of antibiotics by Thayer and Martin (1964) has greatly facilitated the isolation of the organism from contaminated sites. Colonies on selective media are often rather smaller than those on non-selective medium and 48 hours' incubation may be needed before colonies are sufficiently large and characteristic to permit easy recognition. For identification by fluorescent antibody staining (Deacon, 1961) or the staphylococcal co-agglutination test (Danielsson and Kronvall, 1974), young 18-hour colonies are preferable to those grown for $\mathbf{4 8}$ hours. For rapid isolation and identification, an ideal medium should permit the development of colonies large enough for recognition after 18 to 24 hours' incubation.

The results summarized in tables I and II suggest that the growth-promoting properties of brain heart infusion base for gonococci are impaired by autoclaving. The filtered medium gave consistently larger colonies than when it had been autoclaved. This was true of both strains which had been subcultured on the autoclaved medium and so might have become acclimatized to it, and primary isolates from urethral pus. As seen in table 1 , the latter tended to produce smaller colonies than the subcultured strains.

Although medium prepared with filtered brain heart infusion is thought to be preferable, the preparation of large amounts of the sterile filtrate presents problems for most laboratories. Sterilization by autoclaving at $115^{\circ} \mathrm{C}$ for 15 minutes gave reason- ably good results although the colonies were rather smaller than those on the filtered medium. Careful control of the autoclaving process is important, and the medium should be exposed to heat for as short a time as possible compatible with sterility being achieved. Cooling is quicker if the medium is distributed in several small containers rather than in one large one. Everall and Morris (1975) autoclaved blood agar base in large and small containers under the same conditions. Colonies of Streptococcus pyogenes and Streptococcus pneumoniae were smaller when grown on medium from the large container which took a longer time to cool down; viable counts were similar on both batches of medium.

Our thanks are due to the World Health Organization for financial support and to $\mathrm{Mr}$ S. Goldsmith and the nursing staff of the Whitechapel Clinic for their help in the collection of specimens.

\section{References}

Danielsson, D. and Kronvall, G. (1974). Slide agglutination method for the serological identification of Neisseria gonorrhoeae with anti-gonococcal antibodies adsorbed to protein A-containing staphylococci. Appl. Microbiol., 27, 368-374.

Deacon, W. E. (1961). Fluorescent antibody methods for Neisseria gonorrhoeae identification. Bull. Wld Hlth Org., 24, 349-355.

Everall, P. H. and Morris, C. A. (1975). Some observations on cooling in laboratory autoclaves. J. clin. Path., 28, 664669.

Thayer, J. D. and Martin, J. E., Jr. (1964). A selective medium for the cultivation of $N$. gonorrhoeae and $N$. meningitidis. Publ. Hlth Rep. (Wash.), 79, 49-57. 